\title{
Patterns of pre-donation deferral in voluntary blood donors with its impact on the donor pool- A study in a tertiary care hospital
}

\author{
Anegundi R. ${ }^{1 *}$, Divyashree B N. ${ }^{2}$ \\ DOI: https://doi.org/10.17511/jopm.2021.i01.09 \\ 1* Reshma Anegundi, Assistant Professor, Department of Pathology, PES Institute of Medical Science and Research, Kuppam, Andhra \\ Pradesh, India. \\ 2 Divyashree B N, Assistant Professor, Department of Pathology, PES Institute of Medical Science and Research, Kuppam, Andhra Pradesh, \\ India.
}

\begin{abstract}
Background: The prime responsibility of a Blood Transfusion Service is to provide a very safe, sufficient and timely supply of blood and its components to those in need. In fulfilling this responsibility, the Blood Transfusion Service should ensure that the act of blood donation is safe and causes no harm to the donor. Aims and objectives: To estimate the incidence of pre-donation deferral in a tertiary care institute and to estimate various factors for donor deferral. Material and methodology: A retrospective analysis of donors data was collected from January 2019 to December 2019 from the donor deferral registry maintained in the blood bank. In this study, the subjects who visited our blood bank or arrived at a voluntary blood donation camp for purpose of donating blood were screened by donor questionnaire and basic physical examination done with recording vital signs(temperature, blood pressure, pulse rate) followed by hemoglobin estimation and blood grouping. Results: In the present study, 456 donors were deferred from donation. The deferral rate was $13.6 \%$. Deferral rate was high among males. The majority of deferrals, were temporary deferrals, $380(83.33 \%)$ and $76(16.66 \%)$ were permanent deferrals. Anemia was the most common cause among temporary deferrals constituting $56.05 \%$ of temporary deferrals and $46.71 \%$ of total deferrals. Conclusion: Attempts should be made to create awareness among potential donors by conducting health talks, distributing educational pamphlets, counselling donors during donation and encouraging them for future donations.
\end{abstract}

Keywords: Donor deferral, Temporary, Permanent, Anemia

Corresponding Author

Reshma Anegundi, Assistant Professor, Department of Pathology, PES Institute of Medical Science and Research, Kuppam, Andhra Pradesh, India. Email: rashmi.raghavendra703@gmail.com
How to Cite this Article

Anegundi R, Divyashree B N. Patterns of predonation deferral in voluntary blood donors with its impact on the donor pool- A study in a tertiary care hospital. Trop J Pathol Microbiol. 2021;7(1):55-59. Available From

https://pathology.medresearch.in/index.php/jopm/ar ticle/view/513
To Browse

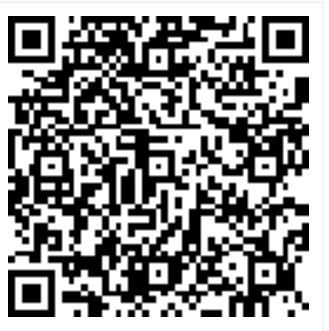

Manuscript Received 2021-02-05

Conflict of Interest No

(c) 2021 by Reshma Anegundi, Divyashree B N and Published by Siddharth Health Research and Social Welfare Society. This is an Open Access article licensed under a Creative Commons Attribution 4.0 International License

Review Round 1 2021-02-15

Funding

Nil
Review Round 2 2021-02-22

Ethical Approval https://creativecommons.org/licenses/by/4.0/ unported [CC BY 4.0].
Review Round 3

Accepted 2021-02-27

Note 


\section{Introduction}

The prime responsibility of the Blood Transfusion Service is to provide a very safe, sufficient and timely supply of blood and its components to those in need. In fulfilling this responsibility, the Blood Transfusion Service should ensure that the act of blood donation is safe and causes no harm to the donor[1].

Individuals who are disqualified from donating blood are known as deferred donors[2]. Deferrals can be temporary or permanent. All deferral donors are expected to be treated with due respect and care confidentially and should be given a clear explanation of the reason for the deferral and an opportunity to ask questions[3]. This study evaluates the incidence and various reasons for donor deferral.

\section{Aims and Objectives}

01. To estimate the incidence of pre-donation deferral in a tertiary care institute.

02. To estimate various factors for donor deferral.

\section{Material and Methodology}

The present study involved voluntary donors who wished to donate blood from January 2019 to December 2019. Our blood bank is attached to a tertiary care teaching hospital with facilities for collection, preparation, storage of blood and its components and issue of blood /components to inpatients, out-patients and local hospitals.

We collected blood both from voluntary donors visiting blood bank and from outdoor voluntary blood donation camps. Blood donation camps were conducted in and around the blood bank covering a $150 \mathrm{~km}$ radius. A retrospective analysis of donors details was collected from January 2019 to December 2019 from the donor deferral registry maintained in the blood bank.

Donors were selected and deferred as per guidelines of Drug and Cosmetic Act 1940 and supplemented by Guidelines of Directorate General of Health Services guidelines, Ministry of Health and Family welfare (2003) and National AIDS Control Organization (NACO).

In this study, the subjects who visited our blood bank or arrived at an outdoor voluntary blood donation camp for purpose of donating blood were considered as "Donors".
Donors were screened by donor questionnaire and basic physical examination done with recording vital signs(temperature, blood pressure, pulse rate) followed by hemoglobin estimation and blood grouping. Hemoglobin estimation was done by the Hemocue method (Hb 301 analyzer) and blood grouping by slide method. Donors fit for blood donation were given pre-donation counselling and requested for donation. Donors who were deferred from donation were counselled and informed of the reason behind deferral and were categorized as temporary deferral and permanent deferral.

Approval for conducting the study was obtained from the Institutional Ethical Committee.

Statistical Analysis: The data were entered in MS Excel 2007version and further analyzed using Epi Info 7.1. For descriptive analyses, the categorical variables were analyzed by using percentages and the continuous variables analyzed by calculating mean +/- standard deviation.

Inclusion criteria: All blood donors who visited for voluntary blood donation(blood bank/camps) were deferred from donation.

Exclusion criteria: Self deferral donors.

\section{Results}

During the study period 3,332 donors registered for donation, 2876 blood donors donated blood and 456 donors were deferred from the donation(Table 1). The deferral rate was $13.6 \%$. Among the donors deferred, 257(56.35\%) were males and $199(43.64 \%)$ were females. Deferral rate was high among males. The most common age group deferred was between 18-30 years both in males and females followed by $31-40$ years (Table 2 ).

Table 1: Gender wise distribution of selected and deferred donors

\begin{tabular}{|l|l|l|l|}
\hline \multicolumn{1}{|c|}{ Donors } & \multicolumn{1}{|c|}{ Males } & \multicolumn{1}{c|}{ Females } & \multicolumn{1}{c|}{ Total } \\
\hline Selected & 2735 & 141 & 2876 \\
\hline Deferred & 257 & 199 & 456 \\
\hline
\end{tabular}

Table-2: Age group and gender-wise deferred donors

\begin{tabular}{|l|l|l|l|l|}
\hline \multirow{2}{*}{ Age in } & \multicolumn{2}{|c|}{ Males } & \multicolumn{2}{c|}{ Females } \\
\cline { 2 - 5 } & $\begin{array}{l}\text { Number of } \\
\text { deferred donors }\end{array}$ & $\begin{array}{l}\text { Percentage of } \\
\text { deferrals }\end{array}$ & $\begin{array}{l}\text { Number of } \\
\text { deferred donors }\end{array}$ & $\begin{array}{l}\text { Percentage of } \\
\text { deferrals }\end{array}$ \\
\hline$<18$ & 8 & 3.11 & 1 & 0.50 \\
\hline $18-30$ & 204 & 79.37 & 193 & 96.98 \\
\hline $31-40$ & 23 & 8.94 & 4 & 2.01 \\
\hline $41-50$ & 20 & 7.78 & 1 & 0.50 \\
\hline
\end{tabular}




\begin{tabular}{|l|l|l|l|l|}
\hline $51-60$ & 1 & 0.38 & 0 & 0 \\
\hline$>60$ & 1 & 0.38 & 0 & 0 \\
\hline Total & 257 & 100 & 199 & 100 \\
\hline
\end{tabular}

The majority of deferrals were temporary deferrals, $380(83.33 \%)$ and $76(16.66 \%)$ were permanent deferrals (Table 3 ).
Table 3: Number and percentage of temporary and permanent deferral

\begin{tabular}{|c|l|l|}
\hline Type & Number of deferral donors & Percentage of deferral \\
\hline Temporary deferral & 380 & $83.33 \%$ \\
\hline Permanent deferral & 76 & $16.66 \%$ \\
\hline
\end{tabular}

Table 4: Causes of temporary donor deferrals and their percentage

\begin{tabular}{|l|l|l|l|l|l|}
\hline \multicolumn{1}{|c|}{ Cause of deferral } & Males & Females & Total number & Percentage of temporary deferral & Percentage of total deferral \\
\hline Age $<18$ & 8 & 1 & 9 & 2.36 & 1.97 \\
\hline Alcohol & 24 & 0 & 24 & 6.31 & 5.26 \\
\hline Allergy & 2 & 1 & 3 & 0.78 & 0.65 \\
\hline Anemia & 56 & 157 & 213 & 56.05 & 46.71 \\
\hline Dental extraction & 0 & 1 & 1 & 0.26 & 0.21 \\
\hline Ear piercing & 2 & 0 & 2 & 0.52 & 0.43 \\
\hline Fever/cough/cold & 25 & 3 & 28 & 7.36 & 6.14 \\
\hline Low weight/Under weight & 14 & 8 & 22 & 5.78 & 4.82 \\
\hline Medications & 22 & 3 & 25 & 6.57 & 5.48 \\
\hline Menstrual history & 0 & 6 & 6 & 1.57 & 1.31 \\
\hline Previous history of donation & 5 & 0 & 5 & 1.31 & 1.09 \\
\hline Smoking & 3 & 0 & 3 & 0.78 & 0.65 \\
\hline Skin rashes & 8 & 1 & 9 & 2.36 & 1.97 \\
\hline Surgery history & 6 & 2 & 8 & 2.10 & 1.75 \\
\hline Tattoo & 18 & 2 & 20 & 5.26 & 4.38 \\
\hline Throat Infections & 2 & 0 & 2 & 0.52 & 0.43 \\
\hline Total & 195 & 185 & 380 & 100 & 83.33 \\
\hline
\end{tabular}

Table 5: Causes of permanent donor deferrals and their percentage

\begin{tabular}{|l|l|l|l|l|l|l|}
\hline \multicolumn{1}{|c|}{ Cause of Permanent deferral } & Males & Females & Total number & Percentage of permanent deferral & \multicolumn{1}{c|}{ Percentage of total deferral } \\
\hline Age $<65$ & 1 & 0 & 1 & 1.31 & 0.21 \\
\hline Asthma & 2 & 0 & 2 & 2.63 & 0.43 \\
\hline Epilepsy & 0 & 1 & 1 & 1.31 & 0.21 \\
\hline High Blood pressure & 36 & 2 & 38 & 50.00 & 8.33 \\
\hline Low Blood pressure & 18 & 9 & 27 & 35.52 & 5.92 \\
\hline Thyroid disorders & 3 & 2 & 5 & 6.57 & 1.09 \\
\hline Tuberculosis history & 2 & 0 & 2 & 2.63 & 0.43 \\
\hline Total & 62 & 14 & 76 & 100 & 16.66 \\
\hline
\end{tabular}

The various causes for temporary and permanent deferrals and their relative proportions are shown in Table 4 and Table 5.

Anemia was the most common cause among temporary deferrals constituting $56.05 \%$ of temporary deferrals and $46.71 \%$ of total deferrals. Anaemia was the commonest cause in both males and females followed by fever /cough/cold in males and low weight/underweight in females. Hypertension was the commonest cause among permanent deferrals in males followed by low blood pressure, which constituted $50 \%$ of permanent deferrals and $8.33 \%$ among total deferrals.
Low blood pressure was the commonest cause of permanent deferral in females followed by hypertension and thyroid disorders on treatment.

\section{Discussion}

Selecting a correct donor by strict adherence to the guidelines is mandatory for safe transfusion practice. In the current study, the overall deferral rate was $13.6 \%$. A comparison of deferral rate in different studies is shown in Table 6.

Table 6: Comparison of donor deferral percentage in different studies 


\begin{tabular}{|l|l|l|}
\hline \multicolumn{1}{|c|}{ Author name } & Study period & \multicolumn{1}{c|}{ Total deferral percentage } \\
\hline Taneja K et al. & 1 year & $17.1 \%$ \\
\hline Okoroiwu H U et al & 1 year & $8.69 \%$ \\
\hline Kulkarni N & 1 year & $4.27 \%$ \\
\hline Kumar S H et al. & 3 years & $13.1 \%$ \\
\hline Vimal M et al. & 4 years & $14.87 \%$ \\
\hline Present study & 1 year & $13.6 \%$ \\
\hline
\end{tabular}

Among the deferrals most of them were in the age group of $18-30$ years(96.98\%). In similar studies done by Kulkarni $\mathrm{N}$ et al. most of the deferred donors were in the age group of 18-38 years $(74.33 \%)$ and a study done by Singh $\mathrm{P}$ et al. majority of donors were between 21-29 years.

In the present study, the deferral rate was high in males when compared to females with a ratio of 1.29:1. Similar study done by Taneja et al. most deferred donors were males(66.6\%) compared to females(33.3\%). Among the deferrals, temporary causes of deferrals constituted $83.33 \%$ and permanent causes for deferrals constituted $16.66 \%$.

Anemia was the most common cause in both males and females constituting $56.05 \%$ in our study. In a study done by Kumar $\mathrm{S} \mathrm{H}$ et al, Singh $\mathrm{P}$ et al. and Chenna $\mathrm{D}$ et al. anemia was the most common cause constituting $54.6 \%, 27.0 \%$ and $48.7 \%$ respectively. The minimal haemoglobin cutoff is set at $12.5 \mathrm{gm} \%$, which is done to ensure both donor safety and appropriate haemoglobin content in the donated unit. A large majority of the donor population in a developing country, like India, is deferred due to temporary causes.

The causes of anemia could be due to nutritional deficiency, blood loss, anemia of chronic disease, and so on. Anemia due to nutritional deficiency is a worldwide problem with the highest prevalence in developing countries like India. The most common cause of nutritional deficiency is iron deficiency. Iron deficiency could be due to inadequate intake or poor bioavailability of dietary iron (only $5 \%-10 \%$ is absorbed) or due to excessive loss of iron from the body (malaria/hookworm infestation)[9].

Apart from anemia, the other most common causes among temporary deferrals were fever/cough/cold(7.36\%) followed by medication (6.57\%) and alcohol consumption in less than 72 hours(6.31\%). A study done by Kumar S H et al. medications $(10.7 \%)$, infections $(7.6 \%)$ and miscellaneous causes were $(5.1 \%)$ and a study done by Chauhan $\mathrm{C}$ et al. alcohol consumption within the last 24 hours $(17.68 \%)$ was a second common cause.
Increasing awareness before the conduction of voluntary blood donation camps and regular talks in the community can reduce the deferrals due to alcohol consumption.

Analysis of permanent deferral donors showed hypertension as the commonest cause constituting $50 \%$ followed by low blood pressure(35.52\%). Results compared to a study done by Shariff $\mathrm{M} \mathrm{H}$ et al. and Vimal $\mathrm{M}$ et al. also reported hypertension as the most common cause. In a study done by Hao J et al. $11.3 \%$ of respondents were in the hypertensive range and it was concluded that hypertension awareness can be created during blood donation.

Additionally, our findings indicate that an educational pamphlet at the time of donation is valuable to donors to increase awareness among the community. Overall, these findings suggest that increasing hypertension awareness as part of a blood donation screening is not only needed but also useful as a public health measure.

\section{Conclusion}

The cause for deferral varies from region to region. The majority of the donors are deferred due to temporary causes. Hence attempts should be made to create awareness among potential donors by conducting health talks, distributing educational pamphlets, counselling donors during donation and encouraging them for future donations.

\section{What does the study add to the existing knowledge?}

Regular health camps can be conducted and proper measures can be given so that temporary deferrals can be brought back to the potential donor pool.

\section{Author's contributions}

Dr. Reshma Anegundi: Concept, study design

Dr. Divyashree B N: Manuscript preparation

\section{Reference}

01. National AIDS Control Organization. Standards for Blood Banks \& Blood Transfusion Services. New Delhi(India)- Ministry of Health and Family Welfare, Government of India. 2007.

[Crossref] 
02. Taneja K, Bhardwaj K, Arora S, Agarwal A. Analysis of the reasons for deferral of prospective blood donors in a Tertiary Care Hospital in North India. J Appl Hematol. $2015 ; 6 ; 154-6$.

[Crossref]

03. Okoroiwu H U, Asemota E A. Blood donors deferral prevalence and causes in a tertiary health care hospital, southern Nigeria. BMC Health Serv Res. 2019;19;510.

[Crossref]

04. Kulkarni N. Analysis of donor deferral in blood donors. Journal of Evolution of Medical and Dental Sciences. 2012;1(6)1076-83.

[Crossref]

05. Kumar SH, Sudhamani S, Roplekar P. Analysis of pre donation deferral of blood donors in a tertiary care hospital. J Sci Soc. 2019;46;86-9. [Crossref]

06. Vimal M, Sowmya S, Nishanthi A, Ramya G. Evaluation of blood donor deferral causes- a retrospective study from South India. Annals Pathol Lab Medic. 2016;3(6)A605-11.

[Crossref]

07. Singh P, Jaiswal VK, Verma N, Rathi M. Pattern of blood donor deferral in a tertiary hospital of western UP- A five -year study review. Rec Adv Path Lb Med. 2016;2(3\&4)16-19.

[Crossref]
08. Chenna D, Shastry S, Murugesan M, Baliga PB. Implication of deferral pattern on the donor pool- Study at a Tertiary Care Hospital. J Appl Haematol. 2015;6;111-4.

[Crossref]

09. Bahadur S, Pujani M, Jain M. Donor deferral due to anemia- A tertiary care centre-based study. Asian J Transfus Sci. 2011;5;53-5.

[Crossref]

10. Chauhan C, Chauhan R, Seema A, Dutta $S$, Joshi H. Pattern and outcome of donor deferral? - Need of hour. Int J Res Med Sci. 2018 Jan;6(1)289-92.

[Crossref]

11. Shariff $M H$, Sadiqunissa, Sultana $Q$. Impact of blood donor deferrals on blood availability in a tertiary care centre of Dakshina Kannada. Indian Journal of Pathology and Oncology. JulSept 2016;3(3)376-78.

[Crossref]

12. Hao J, McAvoy J, Wickberg L, Kerrigan C, Kreiger L, Sikavi $C$ et al. Is blood donation an opportunity for hypertension awareness?. Transfus Med. 2016 Apr;26(2)89-98.

[Crossref] 